\title{
28 Research Square \\ Cost-Effectiveness Analysis of Genomic Profiling in Early Breast Cancer in Colombia
}

Leonardo Rojas ( $\square$ llrojas@colsanitas.com )

Clínica Colsanitas https://orcid.org/0000-0002-7865-5424

María Rojas-Reyes

Fundación Cardioinfantil Instituto de Cardiología: Fundacion Cardioinfantil Instituto de Cardiologia

Diego Rosselli

Pontificia Universidad Javeriana

Andres F. Cardona

Clinica del Country

\section{Research article}

Keywords: breast cancer, personalized medicine, cost-effectiveness

Posted Date: August 24th, 2021

DOI: https://doi.org/10.21203/rs.3.rs-264520/v2

License: (c) (i) This work is licensed under a Creative Commons Attribution 4.0 International License.

Read Full License 


\section{Abstract}

Background: In Colombia, the best strategy to establish indication for adjuvant chemotherapy in early breast cancer (EBC) remains unknown. This study aimed to identify the cost-effectiveness of various strategies to establish the necessity of adjuvant chemotherapy.

Methods: This study used an adapted decision-analytic model to compare cost and outcomes of care that includes Oncotype DX ${ }^{\mathrm{TM}}$ (ODX) or Mammaprint ${ }^{\mathrm{TM}}$ (MMP) tests with routine care without ODX or MMP tests (adjuvant chemotherapy for all patients) over a 5-year time horizon from the perspective of the Colombian National Health System (NHS; payer). Data were obtained from published literature and clinical trial database. The study population comprised women with hormone-receptor-positive (HR+), HER2-negative, lymph-node-negative (LNO) EBC with high-risk clinical criteria for recurrence. The outcome measures were incremental cost-effectiveness ratio (ICER; 2019 United States dollar per quality-adjusted life-year [QALY] gained) and net monetary benefit (NMB).

Results: ODX increases QALYs by 0.05 and MMP by 0.03 with savings of $\$ 2,445$ and $\$ 570$ compared with the standard strategy, respectively. ICER for ODX was $-\$ 41,857$ and that for MMP was $-\$ 18,253$ per QALY; NMB was $\$ 2,821$ and $\$ 771$, respectively. Both tests were cost-effective under the defined threshold. When the two tests were compared, ODX was more cost-effective than MMP. Sensitivity analysis revealed that with a threshold of 1 gross domestic product per capita, ODX will be cost-effective in $95.5 \%$ of the cases compared with $70.2 \%$ cases involving MMP. Probabilistic sensitivity analysis revealed that ODX was a consistently superior strategy.

Conclusions: Genomic profiling using ODX or MMP tests to define the need of adjuvant chemotherapy treatment in patients with HR+ and HER2- EBC is a cost-effective strategy that allows Colombian NHS to maintain budget.

\section{Background}

Breast cancer tumors are the most frequently occurring type of tumors; this cancer type is the leading cause of cancer-related death in women in Colombia, with annual incidence of 48.3 and mortality of 13.1 per 100,000 women (1). Adjuvant chemotherapy reduces the risk of recurrence and increases overall survival; however, it involves a risk of associated toxicity, decreased quality of life, and a significant burden on the healthcare system (2-4). The risk of recurrence determines a patient's eligibility for adjuvant chemotherapy. Several clinicopathological parameters are considered to determine the risk of recurrence, such as lymph node involvement, tumor size, subtype and histological grade, lymphovascular invasion, proliferation markers, hormone-receptor (HR) status, and HER2/neu $(5,6)$. Adjuvant chemotherapy may not be recommended in patients with HR-positive (+) and HER2-negative (-) early breast cancer (EBC) (2). In this population, other clinical criteria, such as tumor size, the degree of differentiation, and patient age, can be taken into consideration (7). However, recommendation based solely on clinical criteria may lead to a significant proportion of these patients being exposed to the adverse effects of chemotherapy and deterioration of quality of life with limited or uncertain benefit (8). 
Recently, quantitative tests evaluating gene expression using microarray and reverse-transcription polymerase chain reaction techniques were developed to better establish the prognosis of patients with EBC with an HR + and HER2 - status. Two of these techniques are Oncotype DX ${ }^{\mathrm{TM}}$ (ODX; Genomic Health, Redwood City, CA) and Mammaprint ${ }^{\text {TM }}$ (MMP; Agendia, Irvine, CA) $(9,10)$. Both techniques have been validated in different studies and proven more accurate at estimating the recurrence risk compared with clinical parameters and other algorithms such as Adjuvant! Online and Nottingham Prognostic Index (NPI) (11-13). Furthermore, there are no relevant variations in test results among genetically different populations such as Latin-American patients (14). In Colombia, according to guidelines, recommendations, and clinical practice, the decision about adjuvant chemotherapy in patients with HR + and Her2 - EBC is based on clinical and pathologic characteristics, and Oncotype DX ${ }^{\mathrm{TM}}$ (ODX) or Mammaprint ${ }^{\text {tM }}$ (MMP) are recommended and approved for the support this decision.(15). The costs of performing ODX or MMP are assumed by Colombian National Health System (NHS).

Direct costs of care for patients with breast cancer are high, and a significant proportion of these are incurred from chemotherapy, which includes treatment of its side effects. Therefore, a strategy that allows an adequate estimate of the risk of recurrence and identification of patients who will benefit from adjuvant chemotherapy will facilitate healthcare cost reductions. This study aimed to determine which of the following interventions was more cost-effective for patients with HR + and HER2 - EBC with high-risk clinical criteria defined as that used in the Microarray in Node-Negative Disease May Avoid Chemotherapy trial:(16) administer adjuvant chemotherapy in all patients (standard intervention) or define treatment indication based on results from ODX or MMP genomic tests.

\section{Methods}

\section{Overview}

An economic cost-effectiveness study evaluating the performance of ODX or MMP test was performed in a cohort of patients with HR + and HER-2 - EBC, without lymph node involvement (LNO) and with high risk of recurrence defined by clinical criteria. Table 1 summarizes the scope of our model. Following the suggestions of the World Health Organization, we compared the incremental cost-effectiveness ratio (ICER) with 1 gross domestic product (GDP) per capita and 3 GDP per capita, until more precise threshold estimates become available in Colombia $(17,18)$. The GDP per capita data were obtained from the Banco de la República reports for the year in which the evaluation was performed (2019) (19). 
Scope of the economic analysis.

\section{Element Description economic analysis}

\section{Population Women with HR + and HER2- early-stage breast cancer (LNO) with high-risk} clinical criteria as per the MINDACT trial (16).

Interventions $\quad$ 1. Oncotype DX (cutoff points as per the TAlLORx trial) (20).

2. Mammaprint (cutoff points as per the MINDACT trial) (16).

$\begin{array}{ll}\text { Comparator } & \text { Chemotherapy for all } \\ \begin{array}{l}\text { Primary health } \\ \text { economic }\end{array} & \text { Incremental cost per QALY gained and net monetary benefit } \\ \text { outcome } & \end{array}$

$\begin{array}{ll}\text { Perspective } & \text { Colombian NHS } \\ \text { Time horizon } & 5 \text { years } \\ \text { Discount rate } & \begin{array}{l}5 \% \text { per annum. A sensibility analysis was performed with discount rates of } 0 \%, \\ \text { 3.5\%, and } 7 \%(21) .\end{array}\end{array}$

Price year 2019

NHS: National Health System

HR+: HR-positive

HER2-: HER2-negative

LNO: without lymph node involvement

QALY: quality-adjusted life-years

The model was developed using Microsoft Excel ${ }^{\mathrm{TM}}$. This was considered a risk-free study according to local laws (Resolution 8430 of 1993) (22) and was approved by the research and ethics committee of the Faculty of Medicine of the Pontificia Universidad Javeriana, Bogotá, Colombia (Ref. 2018/41).

\section{Effectiveness}

Quality-adjusted life-years (QALYs) were considered as a measurement of care outcomes. Utility valuation weights used were those calculated for the Latin-American population in the USA in 2008 (23). The utilities for each health state of the model were extracted according to those reported in the literature including the effects of adjuvant chemotherapy on the quality of life (24-26). ICER (2019 United Sates dollar [USD] per QALY gained) and net monetary benefit (NMB) were estimated. 


\section{Resource Use and Cost}

The costs were reported as the value of 2019 USD ( 1 USD = 3,281 Colombian pesos, according to an average of 2019 COP market exchange rate obtained from Banco de la República reports) (27), and only direct costs were accounted for.

The following sources were used to estimate costs: (1) In MMP and ODX genomic tests, the prices in the Colombian market (for 2019) consulted with the providers were used and (2) cost-generating events and frequency of use for each state were identified through a) clinical recommendations from clinical practice guidelines and b) a panel of experts. Supplementary Table 1 in Additional file 1 summarizes the resources, cost, and references used.

In this study, only febrile neutropenia as adverse event of chemotherapy was taken into account considering that it is the most frequent severe adverse event of adjuvant chemotherapy in breast cancer $(28-30)$.

A type or base case was designed. This type case involved the use of cost-generating events (i.e., consultations, medications, diagnostic tests, hospitalization, and procedures). Subsequently, the monetary cost for the Colombian NHS of each of the cost-generating events was included.

\section{Model Description}

The model structure was developed by consensus among the authors, and it took into account previous published and validated models (31). The model followed the clinical pathway that is in accordance with the recommendations of the clinical practice guidelines under the assumption that it corresponds to the best available description of usual clinical practice in Colombia (15).

An analytical decision model was developed, in which a cohort of patients with HR+, HER2-, and LNO EBC with high-risk clinical criteria was assigned to the standard intervention in which all patients received chemotherapy or underwent ODX or MMP and, according to the results, were classified as high or low risk.

For patients assigned to the standard intervention (chemotherapy for all), distant recurrence-free survival (DRFS) and overall survival (OS) were estimated according to the information available from the TAILORx trial database (NCT00310180).

From this database, we selected the population that met the high-risk clinical criteria, i.e., a tumor size (T) of $>3 \mathrm{~cm}$ or $>2 \mathrm{~cm}$ and a degree of differentiation of 2 or a $T$ of $>1 \mathrm{~cm}$ and a degree of differentiation of 3 , according with the criteria used in MINDACT trial (16). DRFS and OS were estimated for patients who met these criteria, and they subsequently underwent chemotherapy.

In ODX, this same database was considered, and patients were categorized as high or low risk according to the definitions of the TAILORx trial (20), where high risk corresponds to a score of $\geq 16$ for patients aged $\leq 50$ years or a score of $\geq 26$ for those aged $>50$ years and low risk corresponds to a score of $\leq 15$ for patients aged $\leq 50$ years and $\leq 25$ for those aged $>50$ years. DRFS and OS were similarly estimated. In 
MMP, the possibility of a high- or low-risk classification was considered, and the risk of recurrence and death for each risk category was based on the report of the MINDACT trial in a population with negative nodes (N0).(16) For both tests, high-risk patients received adjuvant chemotherapy and low-risk patients did not (Fig. 1. Title: Recurrence risk classification algorithm. Legend: Decision tree-patients are assigned "chemotherapy for all" or "Oncotype/Mammaprint directed chemotherapy."). The cohort was modeled using a Markov process that had the following three mutually exclusive health states: distant recurrence, distant recurrence-free, and death (death from other causes or from breast cancer) (Fig. 2: Title: Markov model. Legend: Three mutually exclusive health states modeled: distant recurrence, distant recurrence-free, and death (death from other causes or from breast cancer). Initially, all patients were in a recurrence-free state and could subsequently progress into a state of recurrence before dying from breast cancer. Patients who did not present with cancer recurrence had a constant probability of dying from other causes. The events of interest were modeled according to the transition of patients from one state to another in 1month cycles, and their effect on QALY was estimated according to literature reports for these states (26). Similarly, the effect on QALY in patients undergoing chemotherapy was based on literature reports (25).

\section{Model Assumptions}

The most important assumption in our model is the estimation made for QALYs and utilities; however, the process was done according to the recommendations for the country in this regard (17). By contrast, for the population receiving standard intervention (chemotherapy), the estimates were made from the database of a clinical study that might not reflect the conditions of routine clinical practice and there may be differences according to patient races. However, both clinical characteristics and treatments that these patients received were similar to those recommended in different clinical practice guidelines and were contrasted with the panel of experts (15). Furthermore, the database used for modeling contained Latin population data. It was assumed that there was $100 \%$ adherence to the result of ODX or MMP-if the result corresponded to a high-risk status, the patient was assumed to require chemotherapy and, if low risk, no chemotherapy was needed. However, this trend has been reported in a lower percentage in a previous case series (32).

\section{Statistical Analysis}

Deterministic sensitivity analysis (DSA) and probabilistic sensitivity analysis (PSA) were performed. A univariate DSA was developed for the assumptions, probabilities, and costs, whereas other variables of the model were fixed. A tornado diagram was used to show the effect of the variation of these parameters on the incremental NMB. To evaluate the uncertainty of any parameter, a PSA was performed using the Monte Carlo simulation method. The simulation was applied 1,000 times to ensure the reproducibility of the model. Table 2 enlists the variables used as inputs for our model as well as their values, ranges, and distribution parameters applied in DSA and PSA. 
Table 2

Variables, values, and parameters used for DSA and PSA.

\begin{tabular}{|c|c|c|c|c|c|c|c|}
\hline \multirow[t]{2}{*}{ Variable } & \multirow{2}{*}{$\begin{array}{l}\text { Base } \\
\text { Case }\end{array}$} & \multicolumn{2}{|c|}{ Range DSA } & \multicolumn{3}{|c|}{ Distribution and parameters PSA } & \multirow[t]{2}{*}{ Reference } \\
\hline & & Lower & Higher & Distribution & प & $\boldsymbol{\beta}$ & \\
\hline Chemotherapy & 0.939 & 0.925 & 0.950 & Log-normal & -0.06 & 0.01 & \multirow{3}{*}{$\begin{array}{l}\text { Database } \\
\text { NCT00310180 }\end{array}$} \\
\hline DRFS 5 years & 0.966 & 0.955 & 0.974 & Log-normal & -0.03 & 0.01 & \\
\hline \multicolumn{7}{|l|}{ OS 5 years } & \\
\hline ODX high risk & 0.914 & 0.895 & 0.930 & Log-normal & -0.09 & 0.01 & \multirow{6}{*}{$\begin{array}{l}\text { Database } \\
\text { NCT00310180 }\end{array}$} \\
\hline DRFS 5 years & 0.957 & 0.943 & 0.968 & Log-normal & -0.04 & 0.01 & \\
\hline OS 5 years & 0.972 & 0.963 & 0.979 & Log-normal & -0.03 & 0.00 & \\
\hline ODX low risk & 0.974 & 0.965 & 0.981 & Log-normal & -0.03 & 0.00 & \\
\hline \multirow{2}{*}{\multicolumn{7}{|c|}{ DRFS 5 years }} & \\
\hline & & & & & & & \\
\hline MMP high risk & 0.909 & 0.880 & 0.932 & Log-normal & -0.10 & 0.01 & \multirow{6}{*}{$\begin{array}{l}(16) \\
(16)\end{array}$} \\
\hline DRFS 5 years & 0.955 & 0.934 & 0.969 & Log-normal & -0.05 & 0.01 & \\
\hline OS 5 years & 0.949 & 0.928 & 0.963 & Log-normal & -0.05 & 0.01 & \\
\hline MMP high risk & 0.970 & 0.953 & 0.981 & Log-normal & -0.03 & 0.01 & \\
\hline \multirow{2}{*}{\multicolumn{7}{|c|}{ DRFS 5 years }} & \\
\hline & & & & & & & \\
\hline Cost & $\$ 3657$ & $\$ 2926$ & $\$ 4389$ & Gamma & 96.04 & 373.21 & Provider \\
\hline ODX & $\$ 3657$ & $\$ 2926$ & $\$ 4389$ & Gamma & 96.04 & 373.21 & Provider \\
\hline MPT & $\$ 112.62$ & $\$ 79$ & $\$ 155$ & Gamma & 33.84 & 19.36 & (33), (34) \\
\hline Rem.1st year* & $\$ 54.81$ & $\$ 32$ & $\$ 85$ & Gamma & 16.58 & 13.46 & (33), (34) \\
\hline \multirow{2}{*}{$\begin{array}{l}\operatorname{Rem}_{\text {year* }} \geq 2 \mathrm{nd} \\
\text { yen }\end{array}$} & $\$ 478.29$ & $\$ 251$ & $\$ 831$ & Gamma & 10.44 & 148.01 & (33), (34) \\
\hline & $\$ 4724.8$ & $\$ 4,375$ & $\$ 5,083$ & Gamma & 684.17 & 180.64 & (33), (34) \\
\hline chemotherapy* & $\$ 256.4$ & $\$ 219$ & $\$ 309$ & Gamma & 125.06 & 22.93 & (33), (34) \\
\hline Recurrence* & $\$ 1566.78$ & $\$ 1,213$ & $\$ 2,298$ & Gamma & 32.02 & 276.87 & (33), (34) \\
\hline \multicolumn{8}{|l|}{ Palliative care* } \\
\hline Adverse event* & & & & & & & \\
\hline
\end{tabular}




\begin{tabular}{|c|c|c|c|c|c|c|c|}
\hline \multirow[t]{2}{*}{ Variable } & \multirow{2}{*}{$\begin{array}{l}\text { Base } \\
\text { Case }\end{array}$} & \multicolumn{2}{|c|}{ Range DSA } & \multicolumn{3}{|c|}{ Distribution and parameters PSA } & \multirow[t]{2}{*}{ Reference } \\
\hline & & Lower & Higher & Distribution & प & $\beta$ & \\
\hline Utility* & 0.9 & 0.85 & 0.95 & Beta & 7.50 & 92.50 & $(26)$ \\
\hline \multirow{2}{*}{$\begin{array}{l}\text { Recurrence- } \\
\text { free survival }\end{array}$} & 0.55 & 0.44 & 0.66 & Beta & 2.42 & 97.58 & $(26)$ \\
\hline & 0.74 & 0.59 & 0.89 & Beta & 6.17 & 93.83 & $(25)$ \\
\hline \multicolumn{8}{|l|}{$\begin{array}{l}\text { Adjuvant } \\
\text { chemotherapy }\end{array}$} \\
\hline Adverse event & 0.07 & 0.02 & 0.08 & - & - & - & (29), (30). \\
\hline \multicolumn{8}{|l|}{ * monthly } \\
\hline $\begin{array}{l}\text { DSA, determinis } \\
\text { distribution par } \\
\text { MMP, Mammap }\end{array}$ & t; Rem, & $\begin{array}{l}\text { lalysis; } \\
\text { distant r } \\
\text { sion; }\end{array}$ & $\begin{array}{l}\text { A, probs } \\
\text { urrence- }\end{array}$ & $\begin{array}{l}\text { listic sensiti } \\
\text { ee survival; }\end{array}$ & ana & $\begin{array}{l}\text {; } \otimes \text { y } \beta, p r \\
\text { rvival; } 0\end{array}$ & $\begin{array}{l}\text { abilistic } \\
\text { K, Oncotype DX; }\end{array}$ \\
\hline
\end{tabular}

\section{Results}

\section{Clinical Parameters of Patients with High-Risk Status}

Among the 10,273 patients included in the NCT00310180 study, information was available to establish the high-risk criteria for 10,086 patients $(98.17 \%)$. In this population, 2,981 patients $(20.35 \%)$ met the highrisk clinical criteria, the median age was 56.3 years (95\% confidence interval $56.0-56.7$ years), and $68.6 \%$ were postmenopausal. The probability rates of the presence of high and low genomic risks with ODX test in the population of high and low clinical risks were $42.1 \%$ and $57.9 \%$, respectively. Furthermore, $75 \%$ patients aged $\leq 50$ years and $28.8 \%$ patients aged $>50$ years presented with a high genomic risk. The population of high clinical risk that was randomized to receive chemotherapy corresponding to the standard intervention of our analysis was 1,643 , which corresponded to $55.1 \%$ of the total high-clinical risk population. Supplementary Table 2 in Additional file 1 summarizes the main characteristics of the population selected for our analysis.

\section{Survival Analysis}

Among the patients who met the high-risk clinical criteria in ODX group, the estimated 5-year DRFS was $91.4 \%$ and $97.2 \%$ for patients with high and low genomic risks, respectively. The estimated OS rates for this population were $95.7 \%$ and $97.4 \%$ for patients with high and low genomic risks, respectively.

In MMP group, the 5-year DRFS rates were $90.9 \%$ and $94.9 \%$ for patients with high and low genomic risks, respectively. The OS rates for those with high and low genomic risks were $95.5 \%$ and $97 \%$, respectively, according to the report of the MINDACT trial for patients with LNO disease (16). 
For the population who underwent chemotherapy (standard intervention), the estimated 5-year DRFS rate was $94 \%$ and the OS rate was $97 \%$. Supplementary Fig. 1 in Additional file 1 shows the 5 -year DRFS for ODX, MMP, and standard intervention.

\section{Base Case Analysis}

According to the base case analysis for a 5-year time horizon, the total cost for patients who received the standard intervention (chemotherapy for all) was $\$ 13,848$ and the QALY value for this group was 3.76. For the standard intervention, ODX had a higher QALY (3.82) than MMP (3.79). The average cost for the 5-year time horizon for ODX and MMP groups were lower than that of the standard intervention, i.e., $\$ 11,402$ and $\$ 13,278$ respectively, which translated into savings of $\$ 2,445$ for ODX and $\$ 570$ for MMP. ICER for ODX was $-\$ 41,857$ per QALY and that for MMP was $-\$ 18,257$ per QALY. ODX and MMP strategies were dominant in the cost-effectiveness plot (Supplementary Fig. 2 in Additional file 1).

In addition, the two genotyping strategies represented an incremental NMB of $\$ 2,821$ for ODX and $\$ 771$ for MMP, and this was considered when a willingness to pay (WTP) threshold of 1 GDP per capita was considered the base. When two ODX tests were compared, ODX was more cost-effective than MMP. Table 3 summarizes the aforementioned findings. 
Table 3

Cost-effectiveness results

\begin{tabular}{|c|c|c|c|}
\hline & $\begin{array}{l}\text { Chemotherapy } \\
\text { (ChT) }\end{array}$ & $\begin{array}{l}\text { Oncotype DX } \\
\text { (ODX) }\end{array}$ & $\begin{array}{l}\text { Mammaprint }^{\mathrm{m}} \\
\text { (MMP) }\end{array}$ \\
\hline LF & 4.36 & 4.33 & 4.34 \\
\hline QALY & 3.75 & 3.81 & 3.79 \\
\hline Costs & $\$ 13848$ & $\$ 11402$ & $\$ 13278$ \\
\hline Incremental LF & & -0.03 & -0.02 \\
\hline Test vs. ChT & & -0.01 & \\
\hline \multicolumn{4}{|l|}{ ODX vs. MMP } \\
\hline Incremental QALY & & 0.06 & 0.03 \\
\hline Test vs. ChT & & 0.03 & \\
\hline \multicolumn{4}{|l|}{ ODX vs. MMP } \\
\hline Incremental Cost & & $-\$ 2446$ & $-\$ 570$ \\
\hline Test vs. QT & & $-\$ 1875$ & \\
\hline \multicolumn{4}{|l|}{ ODX vs. MMP } \\
\hline ICER (per QALY) & & $-\$ 41857$ & $-\$ 18257$ \\
\hline Test vs. QT & & $-\$ 68983$ & \\
\hline \multicolumn{4}{|l|}{ ODX vs. MMP } \\
\hline Incremental NMB (per QALY) & & $\$ 2821$ & $\$ 771$ \\
\hline Test vs. ChT & & $\$ 2050$ & \\
\hline ODX vs. MMP & & & \\
\hline
\end{tabular}

\section{Sensitivity Analysis}

Regarding DSA, variables that were considered at the discretion of the researchers and the panel of experts were defined as having greater uncertainty for the model, which included a) utilities during adjuvant chemotherapy, recurrence, and drug-free period recurrence and b) costs for chemotherapy, adverse events, treatment to recurrence, and palliative care. Supplementary Fig. 3 in Additional file 1 shows the tornado diagram for the DSA for ODX in QALY. 
In our analysis, the variable with the greatest influence was the monthly cost of adjuvant chemotherapy. Notably, we observed that the variation in utility values did not have a significant effect. This suggested that despite the limitations imposed by their estimation from populations other than that of Colombia, they do not significantly affect our findings.

Similar findings were obtained in the DSA for MMP (Supplementary Fig. 4 in Additional file 1). Given that chemotherapy treatment costs $<\mathbf{\$} 274$, MMP may not be cost-effective. In the PSA, considering that a threshold of 1 GDP per capita for 2019 corresponded to $\$ 6,428$, ODX had $95.5 \%$ probability of being costeffective and MMP had $70.2 \%$ compared with the standard strategy (chemotherapy for all patients). Comparison of the two tests revealed that ODX had $99.1 \%$ probability of being more cost-effective than MMP. Figure 3 (Title: Probabilistic sensitivity analysis. Legend: Scatterplot on the incremental costeffectiveness plane, comparing each test with chemotherapy for all in the base-case analysis.) shows the PSA for QALY.

\section{Discussion}

The use of adjuvant chemotherapy in EBC has been beneficial to some patients by decreasing tumor recurrence and increasing OS; however, in certain cases, chemotherapy can generate serious adverse events that cause deterioration in the quality of life and substantial increase in health $\operatorname{costs}(2,4,24)$. Furthermore, in this population, it is typically difficult to determine whether chemotherapy should be administered(35).

Gene expression profiles such as MMP and ODX have established more precisely the prognosis and helped define the benefit of chemotherapy treatment in an individual assessment. This results in the accurate selection patients and avoids unnecessary therapies; however, performing these tests may imply an additional cost $(16,20)$. These tests are recommended by different clinical practice guidelines, especially for patients with a high clinical risk, and they are often used in Colombian oncology practice (15).

In this study, which was possibly the first in Colombia, we found that performing ODX or MMP is a costeffective strategy for the health system and generates economic savings. In our model, although we observed an increase in life-years after comparing the performance of standard strategy (4.36) with that of MMP (4.34) or ODX (4.33), these results are at the expense of deterioration in the quality of life that can be attributed to chemotherapy treatment, resulting in a benefit in terms of QALY that favors MMP or ODX ( 0.03 and 0.05 , respectively). Despite the possibility of these differences in improvements in both life-year and QALY not being statistically or clinically significant, the capability of MMP or ODX tests to better select patients for chemotherapy results in the reduction of the cost of chemotherapy treatment. The incremental NMB for ODX is $\$ 2,741$ and that for MMP is $\$ 771$, indicating that genomic profiling using these tests generates an economic surplus compared with the standard strategy in the WTP threshold defined for Colombia as 1 GDP per capita for the QALY analysis. In this case, the cost to obtain the benefit is less than the maximum amount that the Colombian NHS would consider paying for this benefit. In the sensitivity 
analysis, MMP could not be considered economically acceptable only when the costs of adjuvant chemotherapy were $<\$ 274$ per month of treatment.

Notably, even when the system is not willing to pay any cost for this benefit, i.e., with a WTP threshold of $\$ 0$, both tests are cost-effective (incremental NMB for ODX at $\$ 2,446$ and incremental NMB for MMP at $\$ 570)$.

From the perspective of the Colombian NHS, for a WTP of 1 GDP per capita, there is a $95.5 \%$ and $70.2 \%$ probability that ODX and MMP tests will be cost-effective, respectively. Importantly, even with a WPT of COP 0 , the probability that the tests are cost-effective is high, especially for one of the tests $(99.1 \%$ for ODX and $66.7 \%$ for MMP).

Our results are in agreement with those reported previously in the literature. A cost-effectiveness study of the genomic profile for breast cancer conducted in Canada that included information from the TAILORx(20) and MINDACT (16) trials showed that the genomic profiling of breast cancer patients using ODX or MMP tests is a cost-effective strategy below the threshold of WTP defined for this study when compared with the standard management, i.e., the absence of any test. In this analysis, ODX has a $89.2 \%$ probability and MMP has $89.2 \%$ probability of being cost-effective for a WTP threshold of Canadian dollar $50,000(36)$.

Several systematic reviews have concluded that performing the genomic profile in EBC to define adjuvant chemotherapy treatment is a cost-effective strategy (37-39). However, other analyses have shown that this finding is not consistent in all population subgroups and that ODX genomic profile is cost-effective when performed in a high-clinical risk population and not in a low-clinical risk population. A costeffectiveness study conducted by the UK National Institute for Excellence in Health and Care found that neither ODX nor MMP was cost-effective from the perspective of the UK health system(40). No predictive role of the benefit of chemotherapy was considered for ODX or MMP. Notably, at the time of performing this analysis, the results of the TAILORx trial were unknown, which demonstrated the ability of ODX to establish not only prognosis but also the benefit of adjuvant chemotherapy(20). When the predictive role of ODX to establish the benefit of adjuvant chemotherapy was included, this test was cost-effective, particularly for patients with high clinical risk (for this study defined as the subgroup with NPI > 3.4) a finding similar of ours(40). In MMP, despite the results of the MINDACT trial (16), this test was not costeffective(40).

Several cost-effectiveness studies have not considered this analysis for clinical risk subgroups, which could favor the new test as cost-effective, and for this reason, the incorporation of clinical characteristics into the cost-effectiveness models is recommended(41). In contrast, the performance of MMP is only recommended in patients with high clinical risk, and the combination of these clinical criteria with ODX result can increase its prognostic capacity $(42,43)$. Only patients with high-risk clinical criteria were included in our model, which is a conservative strategy, demonstrating that performing MMP or ODX in this population is a cost-effective strategy. Hall et al. found results similar to ours in the United Kingdom when they used a model that also included patients with high clinical risk with lymph node involvement 
(31). In addition to MMP and ODX, other tests such as PAM-50 (Prosigna ${ }^{\mathrm{TM}}$ ), MammaTyper ${ }^{\mathrm{TM}}$, IHC4, and IHC4-AQUA $^{\mathrm{TM}}$ (NexCourseBreast ${ }^{\mathrm{TM}}$ ) were also evaluated by Hall et al. and found an $86 \%$ probability that gene expression profiles are cost-effective in defining the need for adjuvant chemotherapy in patients with EBC (31).

In our study, when two ODX tests were compared, and they were more cost-effective than MMP with an incremental NMB of $\$ 2,050$ and $99 \%$ probability of being more cost-effective. Our findings suggest that to achieve results similar to those of ODX test, the costs of MMP test should be lower.

Most cost-effectiveness studies have assumed that the relative risk reduction (RRR) for distant recurrence attributed to chemotherapy varies according to different genomic risk groups, i.e., the RRR is 0 for patients with low genomic risk and higher for those with high genomic risk. These assumptions make genomic testing more cost-effective because it can better establish the magnitude of chemotherapy benefit than the traditional clinical criteria. However, the predictive values of these tests, for these cost-effectiveness studies, were based on limited information based on retrospective analysis $(44,45)$. In our model, we considered information from prospective studies with a significant number of patients, in which the predictive role of the tests has been demonstrated, particularly for $\operatorname{ODX}(16,20)$.

Our study has several limitations. Foremost, we were not able to identify QALY for our population. Despite being a methodological limitation, some guidelines recommend QALY as an outcome measure because this measure more comprehensively evaluates health outcomes (17). For our case, it is essential to establish the effect of chemotherapy on the quality of life, and according to our results, they are significant when evaluated from this perspective. Despite these limitations, variations that could exist in the valuations of the utilities do not alter our results, as evidenced by the DSA. Although there could be variations in utilities among different populations, these variations, regardless of their significance, did not seem to affect our results. However, it is essential to assess QALYs and the utilities for the Colombian population, so that more accurate cost-effective evaluations can be performed in different scenarios, especially in those closely related to the quality of life, such as in oncological diseases. As shown in our analysis, if measures of effectiveness, such as years of life, are analyzed, a treatment or strategy will be considered not cost-effective, as its effect on the quality of life will be ignored. Another limitation of our study is the 5-year time horizon, which is relatively short when compared with that used by other costeffectiveness studies. This time horizon includes the main relevant outcomes, especially the secondary event associated with chemotherapy that was considered in our model, which was febrile neutropenia. In this regard, our model is conservative, as it does not account for other adverse events attributable to chemotherapy, such as heart failure or the development of secondary malignancies. These adverse events have a negative effect on the quality of life, risk of death, and increased health costs. Furthermore, by the time of the analysis, only 5-year follow-up data were available for one of the trials used (16), and we preferred to not include survival assumptions in our model.

Considering that genomic profiling using ODX and MMP tests is a cost-effective and cost-saving strategy, establishing the budget effect of these tests could be important to define whether they can be included in Colombia's health benefit plan.

Page $13 / 21$ 


\section{Conclusions}

Genomic profiling using ODX and MMP tests is a cost-effective strategy for the Colombian NHS. This strategy generates savings in the health system when compared with the standard treatment strategy. When these two genomic profiling strategies are compared, ODX is a more cost-effective strategy than MMP and allows for greater savings. These tests should be indicated in a population with HR+, HER2 EBC with high-risk clinical criteria.

\section{List Of Abbreviations}

DRFS Distant recurrence-free survival

EBC Early breast cancer

GDP Gross domestic product

HR Hormone-receptor

ICER Incremental cost-effectiveness ratio

MMP Mammaprint ${ }^{\text {TM }}$

NCTN National Clinical Trials Network

NHS National Health System

NMB Net monetary benefit

NPI Nottingham Prognostic Index

OS Overall survival

ODX Oncotype DX ${ }^{\mathrm{TM}}$

PSA Probabilistic sensitivity analyses

QALY Quality-adjusted life-years

RRR Relative risk reduction

USD United States dollar

WTP Willingness to pay

\section{Declarations}


Ethics approval and consent to participate: This was considered a risk-free study according to local laws (Resolution 8430 of 1993)(22) and was approved by the Research and Ethics Committee of the Faculty of Medicine of the Pontificia Universidad Javeriana Ref. 2018/41.

Consent for publication: Not applicable

Availability of data and materials: This manuscript was prepared using data from datasets [NCT00310180] from the National Clinical Trials Network (NCTN) Data Archive of the National Cancer Institute (46). Data were originally collected from the clinical trial NCT00310180 (Adjuvant chemotherapy guided by a 21-gene expression assay in breast cancer). All analyses and conclusions in this manuscript are the sole responsibility of the authors and do not necessarily reflect the opinions or views of the clinical trial investigators, NCTN, or NCl.

Competing interests: The authors declare that they have no competing interests.

Funding: Not applicable.

Authors' contributions: LR conceived the project, wrote, and prepared the manuscript; MR-R: conceived the project, discussed, and reviewed the manuscript. DR and AFC: discussed and reviewed the manuscript. All authors read and approved the final manuscript.

Acknowledgments: We acknowledge the contributions of Juan Guillermo Ariza, MD, MSc, MBA, in supporting design and providing inputs of economic model. We also thank the National Clinical Trial Network of the US National Cancer Institute for allowing us to use this database and for providing support. We also acknowledge the master program of the Clinical Epidemiology and Biostatistics Department of Faculty of Medicine of Pontificia Universidad Javeriana, Bogotá, Colombia. Leonardo Rojas, MD, was a master student candidate of this program.

\section{References}

1. Ferlay JEM, Lam F, Colombet M, Mery L, Piñeros M, Znaor A, Soerjomataram I, Bray F.. Global Cancer Observatory: Cancer Today. Lyon, France: International Agency for Research on Cancer; 2020 [Available from: https://gco.iarc.fr/today. Accessed 10 Dec 2020.

2. Early Breast Cancer Trialists'. Collaborative G, Peto R, Davies C, Godwin J, Gray R, Pan HC, et al. Comparisons between different polychemotherapy regimens for early breast cancer: meta-analyses of long-term outcome among 100,000 women in 123 randomised trials. Lancet. 2012;379(9814):43244.

3. Harris LN, Ismaila N, McShane LM, Andre F, Collyar DE, Gonzalez-Angulo AM, et al. Use of biomarkers to guide decisions on adjuvant systemic therapy for women with early-stage invasive breast Cancer: American Society of Clinical Oncology Clinical Practice Guideline. J Clin Oncol. 2016;34(10):1134-50.

4. Hassett MJ, O'Malley AJ, Pakes JR, Newhouse JP, Earle CC. Frequency and cost of chemotherapyrelated serious adverse effects in a population sample of women with breast cancer. $\mathrm{J}$ Natl Cancer 
Inst. 2006;98(16):1108-17.

5. Martín-Angulo MA-YM, Villalobos-León ML. Alvarez de Mon Soto M. [Breast Cancer]. Medicine. 2013;11(27):1629-40.

6. Espinosa E, Gamez-Pozo A, Sanchez-Navarro I, Pinto A, Castaneda CA, Ciruelos E, et al. The present and future of gene profiling in breast cancer. Cancer Metastasis Rev. 2012;31(1-2):41-6.

7. Burstein HJ, Curigliano G, Loibl S, Dubsky P, Gnant M, Poortmans P, et al. Estimating the benefits of therapy for early-stage breast cancer: the St. Gallen International Consensus Guidelines for the primary therapy of early breast cancer 2019. Ann Oncol. 2019;30(10):1541-57.

8. Petrelli F, Borgonovo K, Cabiddu M, Lonati V, Barni S. Mortality, leukemic risk, and cardiovascular toxicity of adjuvant anthracycline and taxane chemotherapy in breast cancer: a meta-analysis. Breast Cancer Res Treat. 2012;135(2):335-46.

9. Buyse M, Loi S, van't Veer L, Viale G, Delorenzi M, Glas AM, et al. Validation and clinical utility of a 70gene prognostic signature for women with node-negative breast cancer. J Natl Cancer Inst. 2006;98(17):1183-92.

10. Paik S, Shak S, Tang G, Kim C, Baker J, Cronin M, et al. A multigene assay to predict recurrence of tamoxifen-treated, node-negative breast cancer. N Engl J Med. 2004;351(27):2817-26.

11. Tang G, Shak S, Paik S, Anderson SJ, Costantino JP, Geyer CE Jr, et al. Comparison of the prognostic and predictive utilities of the 21-gene Recurrence Score assay and Adjuvant! for women with nodenegative, ER-positive breast cancer: results from NSABP B-14 and NSABP B-20. Breast Cancer Res Treat. 2011;127(1):133-42.

12. Bueno-de-Mesquita JM, van Harten WH, Retel VP, van 't Veer LJ, van Dam FS, Karsenberg K, et al. Use of 70-gene signature to predict prognosis of patients with node-negative breast cancer: a prospective community-based feasibility study (RASTER). Lancet Oncol. 2007;8(12):1079-87.

13. Bueno-de-Mesquita JM, Sonke GS, van de Vijver MJ, Linn SC. Additional value and potential use of the 70-gene prognosis signature in node-negative breast cancer in daily clinical practice. Ann Oncol. 2011;22(9):2021-30.

14. Bargallo JE, Lara F, Shaw-Dulin R, Perez-Sanchez V, Villarreal-Garza C, Maldonado-Martinez H, et al. A study of the impact of the 21-gene breast cancer assay on the use of adjuvant chemotherapy in women with breast cancer in a Mexican public hospital. J Surg Oncol. 2015;111(2):203-7.

15. Ministerio de Salud y Protección Social de Colombia. Guía de práctica clínica para tratamiento integral, seguimiento y rehabilitación del cáncer de mama. 2da Edición. Guía No 19 Colombia 2017 [Available from: http://gpc.minsalud.gov.co. Accessed 12 Jun 2019.

16. Cardoso F, van't Veer LJ, Bogaerts J, Slaets L, Viale G, Delaloge S, et al. 70-Gene Signature as an Aid to Treatment Decisions in Early-Stage Breast Cancer. N Engl J Med. 2016;375(8):717-29.

17. Instituto de Evaluación Tecnológica en Salud (IETS). Manual para la elaboración de evaluaciones económicas en salud. Bogotá D.C.: IETS; 2014.

18. WHO. Global status report on non-communicable diseases 2010. p 1-162. [Available from: https://www.who.int/chp/ncd_global_status_report/en/. Accessed 10 Sep 2019. 
19. Banco de la Republica Colombia. Producto Interno Bruto (PIB) Bogotá, Colombia2019 [Available from: https://www.banrep.gov.co/es/estadisticas/producto-interno-bruto-pib. Accessed 5 Jan 2020.

20. Sparano JA, Gray RJ, Makower DF, Pritchard KI, Albain KS, Hayes DF, et al. Adjuvant chemotherapy guided by a 21-gene expression assay in breast cancer. N Engl J Med. 2018;379(2):111-21.

21. International Society for Health Economics and Outcomes Research. Pharmacoeconomic guidelines around the world [Internet]. Available from: https://www.ispor.org/PEguidelines/countrydet.asp? $c=43 \& t=1$. Accessed 9 Oct 2019.

22. de Salud M. República de Colombia. Resolución Número 8430 de 1993 (1993). p. 1-19.

23. Zarate V, Kind P, Chuang LH. Hispanic valuation of the EQ-5D health states: a social value set for Latin Americans. Value Health. 2008;11(7):1170-7.

24. Campbell HE, Epstein D, Bloomfield D, Griffin S, Manca A, Yarnold J, et al. The cost-effectiveness of adjuvant chemotherapy for early breast cancer: A comparison of no chemotherapy and first, second, and third generation regimens for patients with differing prognoses. Eur J Cancer. 2011;47(17):251730.

25. Tina Shih YC, Dong W, Xu Y, Shen Y. Assessing the cost-effectiveness of updated breast cancer screening guidelines for average-risk women. Value Health. 2019;22(2):185-93.

26. Hajjar A, Ergun MA, Alagoz O, Rampurwala M. Cost-effectiveness of adjuvant paclitaxel and trastuzumab for early-stage node-negative, HER2-positive breast cancer. PloS one. 2019;14(6):e0217778.

27. Banco de la República Colombia. Tasa representativa del mercado (TRM-peso por dólar) 2019 [Available from: https://www.banrep.gov.co/es/estadisticas/trm. Accessed 3 Jan 2021.

28. Martin M, Segui MA, Anton A, Ruiz A, Ramos M, Adrover E, et al. Adjuvant docetaxel for high-risk, node-negative breast cancer. N Engl J Med. 2010;363(23):2200-10.

29. Jones S, Holmes FA, O'Shaughnessy J, Blum JL, Vukelja SJ, Mclntyre KJ, et al. Docetaxel With Cyclophosphamide Is Associated With an Overall Survival Benefit Compared With Doxorubicin and Cyclophosphamide: 7-Year Follow-Up of US Oncology Research Trial 9735. J Clin Oncol. 2009;27(8):1177-83.

30. Burnell M, Levine MN, Chapman JA, Bramwell V, Gelmon K, Walley B, et al. Cyclophosphamide, epirubicin, and Fluorouracil versus dose-dense epirubicin and cyclophosphamide followed by Paclitaxel versus Doxorubicin and cyclophosphamide followed by Paclitaxel in node-positive or highrisk node-negative breast cancer. J Clin Oncol. 2010;28(1):77-82.

31. Hall PS, Smith A, Hulme C, Vargas-Palacios A, Makris A, Hughes-Davies L, et al. Value of information analysis of multiparameter tests for chemotherapy in early breast cancer: The OPTIMA Prelim Trial. Value Health. 2017;20(10):1311-8.

32. Carlson JJ, Roth JA. The impact of the Oncotype Dx breast cancer assay in clinical practice: a systematic review and meta-analysis. Breast Cancer Res Treat. 2013;141(1):13-22.

33. Gobierno de Colombia. Precios de medicamentos 2019 [Available from: https://www.datos.gov.co/Salud-y-Protecci-n-Social/Precios-Medicamentos/3t73-n4q9. Accessed 10 
Sep 2019.

34. Consultor Salud. Manual tarifario SOAT de salud 2020 [Available from:

https://consultorsalud.com/manual-tarifario-soat-2020-facturacion-de-servicios-de-salud/. Accessed 15 Jan 2020.

35. Hayes DF. Targeting adjuvant chemotherapy: a good idea that needs to be proven! J Clin Oncol. 2012;30(12):1264-7.

36. Ontario H. Gene Expression Profiling Tests for Early-Stage Invasive Breast Cancer: A Health Technology Assessment. Ont Health Technol Assess Ser. 2020;20(10):1-234.

37. Ward S, Scope A, Rafia R, Pandor A, Harnan S, Evans P, et al. Gene expression profiling and expanded immunohistochemistry tests to guide the use of adjuvant chemotherapy in breast cancer management: a systematic review and cost-effectiveness analysis. Health Technol Assess. 2013;17(44):1-302.

38. Rouzier R, Pronzato P, Chereau E, Carlson J, Hunt B, Valentine WJ. Multigene assays and molecular markers in breast cancer: systematic review of health economic analyses. Breast Cancer Res Treat. 2013;139(3):621-37.

39. Marrone M, Stewart A, Dotson WD. Clinical utility of gene-expression profiling in women with early breast cancer: an overview of systematic reviews. Genet Med. 2015;17(7):519-32.

40. Harnan S, Tappenden P, Cooper K, Stevens J, Bessey A, Rafia R, et al. Tumour profiling tests to guide adjuvant chemotherapy decisions in early breast cancer: a systematic review and economic analysis. Health Technol Assess. 2019;23(30):1-328.

41. Wang SY, Dang W, Richman I, Mougalian SS, Evans SB, Gross CP. Cost-Effectiveness Analyses of the 21-Gene Assay in Breast Cancer: Systematic Review and Critical Appraisal. J Clin Oncol. 2018;36(16):1619-27.

42. Sparano JA, Gray RJ, Ravdin PM, Makower DF, Pritchard KI, Albain KS, et al. Clinical and genomic risk to guide the use of adjuvant therapy for breast cancer. N Engl J Med. 2019;380(25):2395-405.

43. Krop I, Ismaila N, Andre F, Bast RC, Barlow W, Collyar DE, et al. Use of biomarkers to guide decisions on adjuvant systemic therapy for women with early-stage invasive breast cancer: American Society of Clinical Oncology clinical practice guideline focused update. J Clin Oncol. 2017;35(24):2838-47.

44. Paik S, Tang G, Shak S, Kim C, Baker J, Kim W, et al. Gene expression and benefit of chemotherapy in women with node-negative, estrogen receptor-positive breast cancer. J Clin Oncol. 2006;24(23):372634.

45. Knauer M, Mook S, Rutgers EJ, Bender RA, Hauptmann M, van de Vijver MJ, et al. The predictive value of the 70-gene signature for adjuvant chemotherapy in early breast cancer. Breast Cancer Res Treat. 2010;120(3):655-61.

46. Gonzalez-Morales S, Perez-Labrada F, Garcia-Enciso EL, Leija-Martinez P, Medrano-Macias J, DavilaRangel IE, et al. Selenium and Sulfur to Produce Allium Functional Crops. Molecules. 2017;22(4).

\section{Figures}




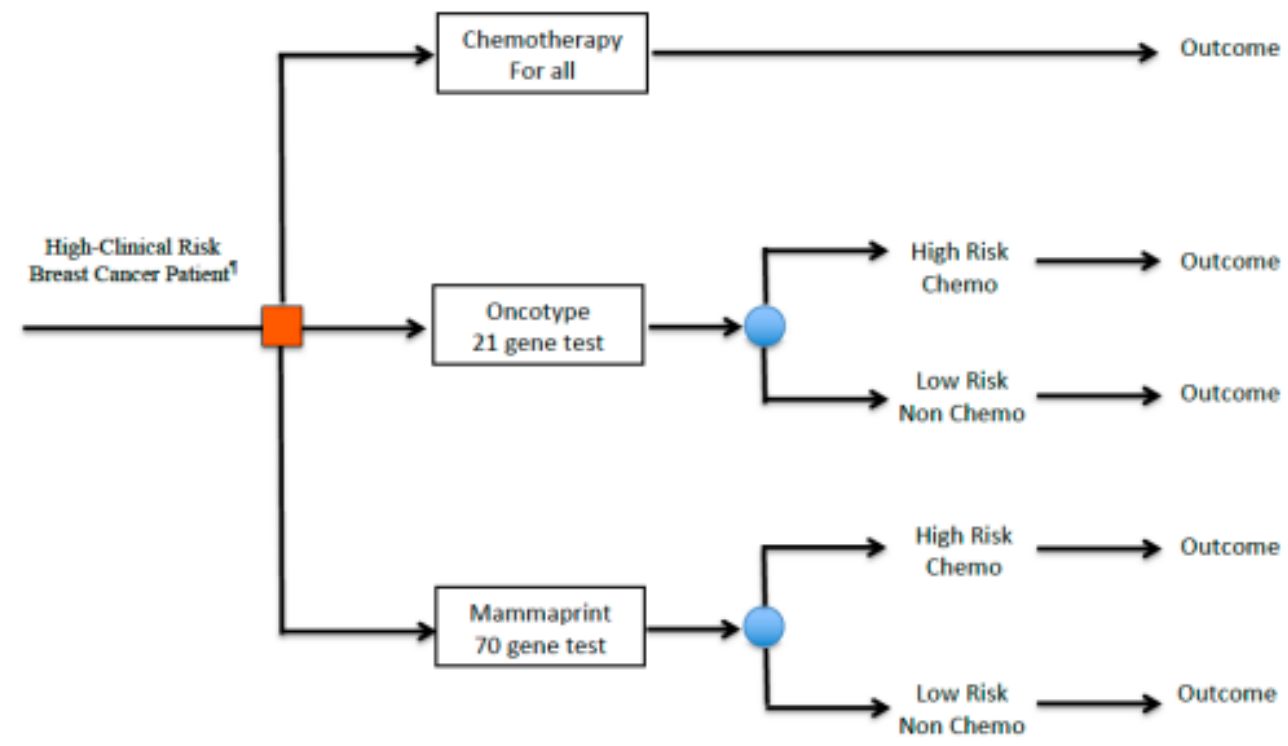

Decision node

Probability node

Chemo $=$ Chemotherapy

१ Defined by:

- Tumoral size $(\mathrm{T})>3 \mathrm{~cm}$,

- $\mathrm{T}>2 \mathrm{~cm}$ y grade of differentiation (GD) 2

- $\mathrm{T}>1 \mathrm{~cm}$ y GD 3

\section{Figure 1}

Recurrence risk classification algorithm. Legend: Decision tree-patients are assigned "chemotherapy for all" or "Oncotype/Mammaprint directed chemotherapy. 


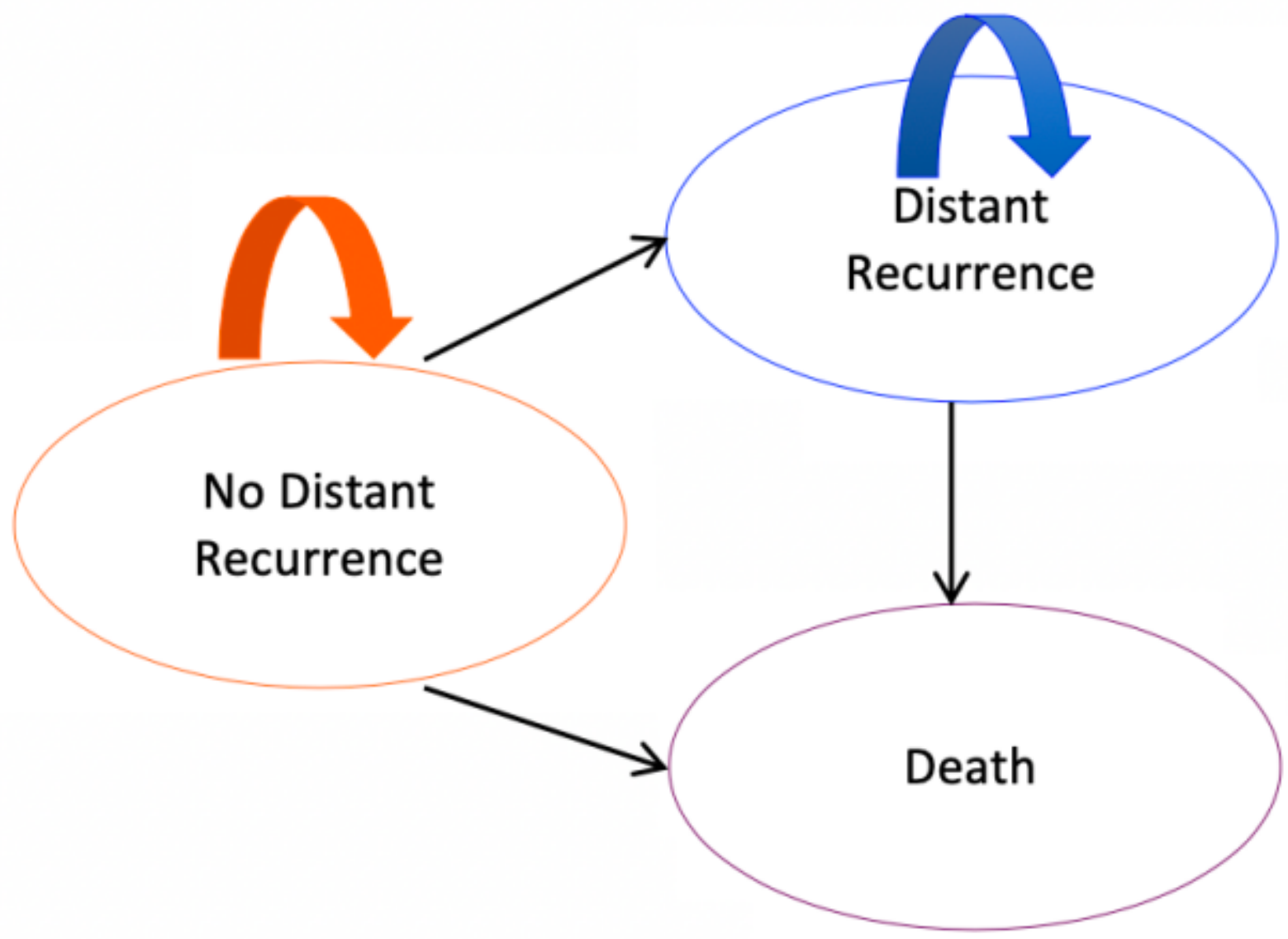

Figure 2

Markov model. Legend: Three mutually exclusive health states modeled: distant recurrence, distant recurrence-free, and death (death from other causes or from breast cancer 


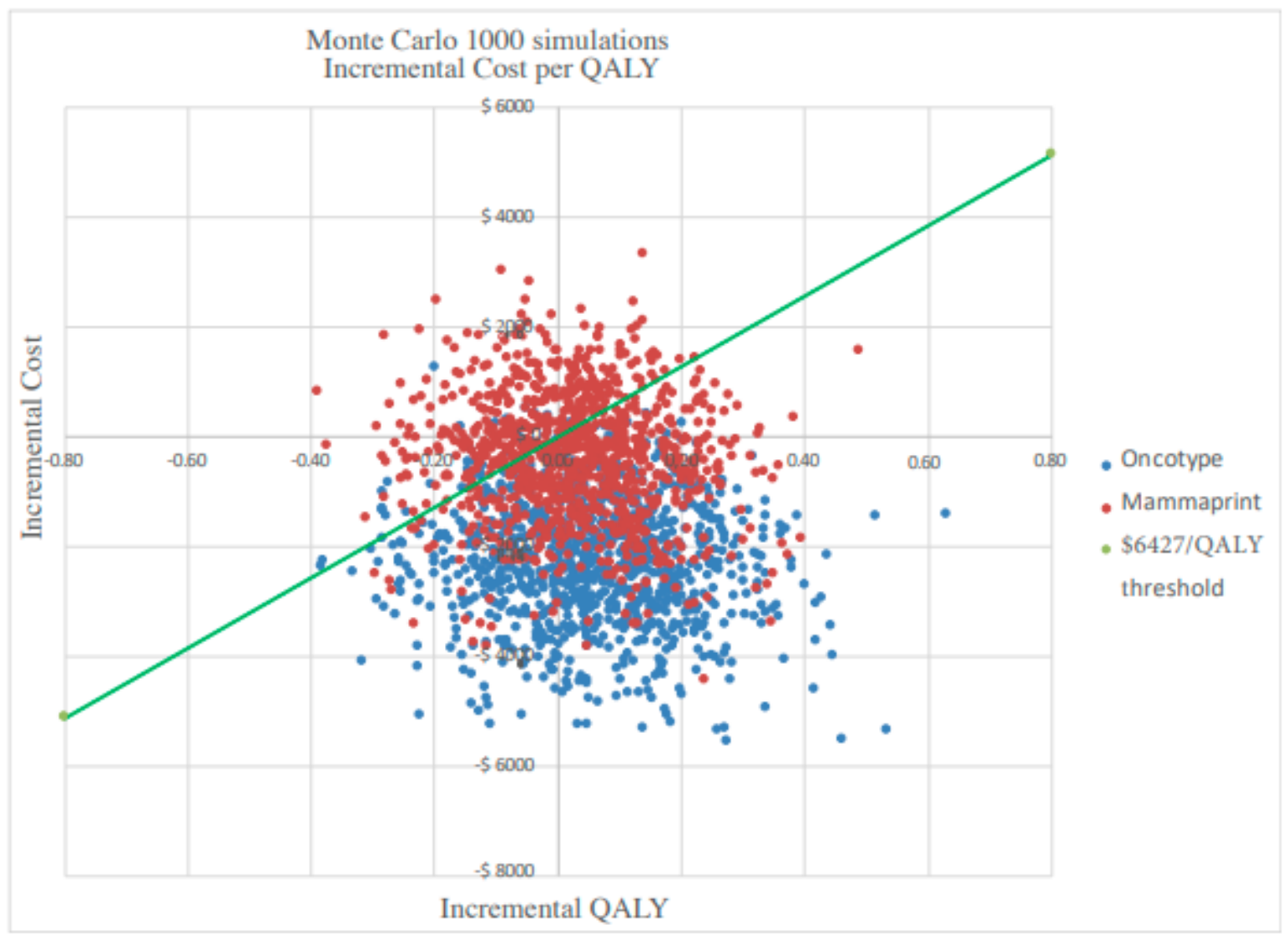

QALY: Quality-adjusted life-year

\section{Figure 3}

Probabilistic sensitivity analysis. Legend: Scatterplot on the incremental cost-effectiveness plane, comparing each test with chemotherapy for all in the base-case analysis.

\section{Supplementary Files}

This is a list of supplementary files associated with this preprint. Click to download.

- Additionalfile1.pdf 